AN EVALUATION OF ENVIRONMENTAL DATA

RELATING TO SELECTED NUCLEAR POWER

PLANT SITES

A SYNTHESIS AND SUMMARY WITH RECOMMENDATIONS

Ishwar P. Murarka, Anthony J. Policastro, John G. Ferrante, Edward W. Daniels, and Gary J. Marmer

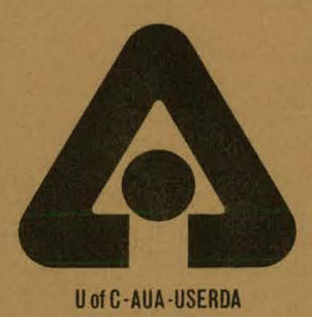

November 1976

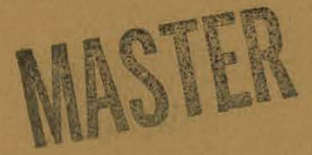

DIVISION OF ENVIRONMENTAL IMPACT STUDIES

ARGONNE NATIONAL LABORATORY

Argonne, Illinois 


\section{DISCLAIMER}

This report was prepared as an account of work sponsored by an agency of the United States Government. Neither the United States Government nor any agency Thereof, nor any of their employees, makes any warranty, express or implied, or assumes any legal liability or responsibility for the accuracy, completeness, or usefulness of any information, apparatus, product, or process disclosed, or represents that its use would not infringe privately owned rights. Reference herein to any specific commercial product, process, or service by trade name, trademark, manufacturer, or otherwise does not necessarily constitute or imply its endorsement, recommendation, or favoring by the United States Government or any agency thereof. The views and opinions of authors expressed herein do not necessarily state or reflect those of the United States Government or any agency thereof. 


\section{DISCLAIMER}

Portions of this document may be illegible in electronic image products. Images are produced from the best available original document. 
The facilities of Argonne National Laboratory are owned by the United States Government. Under the terms of a contract (W-31-109-Eng-38) between the U. S. Fnergy Research and Development Administration, Argonne Universities Association and The University of Chicago, the University employs the staff and operates the Laboratory in accordance with policies and programs formulated, approved and reviewed by the Association.

\section{MEMBERS OF ARGONNE UNIVERSITIES ASSOCIATION}

The University of Arizona Carnegie-Mellon University Case Western Reserve University The University of Chicago University of Cincinnati Illinois Institute of Technology University of Illinois Indiana University Iowa State University The University of Iowa
Kansas State University The University of Kansas Loyola University Marquette University Michigan State University The University of Michigan University of Minnesota University of Missouri Northwestern University University of Notre Dame
The Ohio State University Ohio University

The Pennsylvania State University Purdue University

Saint Louis University Southern Illinois University The University of Texas at Austin Washington University Wayne State University The University of Wisconsin

NOTICE

This report was prepared as an account of work sponsored by the United States Government. Neither the United States nor the United States Energy Research and Development Administration, nor any of their employees, nor any of their contractors, subcontractors, or their employees, makes any warranty, express or implied, or assumes any legal liability or responsibility for the accuracy, completeness or usefulness of any information, apparatus, product or process disclosed, or represents that its use would not infringe privately-owned rights. Mention of commercial products, their manufacturers, or their suppliers in this publication does not imply or connote approval or disapproval of the product by Argonne National Laboratory or the U. S. Energy Research and Development Administration. 
AN EVALUATION OF ENVIRONMENTAL DATA

RELATING TO SELECTED NUCLEAR POWER PLANT SITES

A SYNTHESIS AND SUMMARY WITH RECOMMENDATIONS

by

Ishwar P. Murarka $\Lambda$ nthony J. Policastro

John G. Ferrante

Edward W. Daniels

Gary J. Marmer

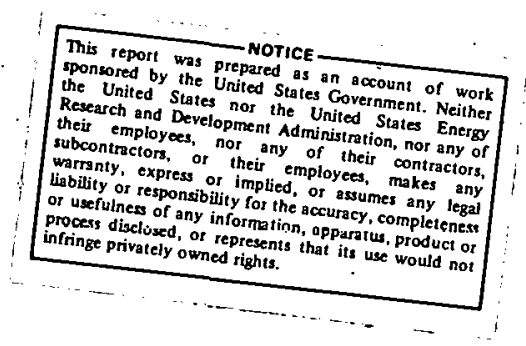

November 1976

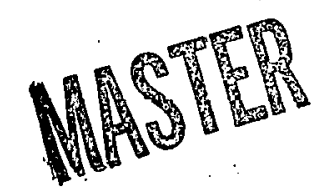

Division of Environmental Impact Studies

Argonne National Laboratory

Argonne, Illinois 60439 
THIS PAGE

\section{WAS INTENTIONALLY LEFT BLANK}




\section{Preface}

The Office of Regulatory Research, U. S. Nuclear Regulatory Commission, has sponsored programs at the Argonne National Laboratory, the Battelle Pacific Northwest Laboratory, and the Oak Ridge National Laboratory for analyzing and evaluating nonradiological environmental data obtained from the monitoring activities at nuclear power plants. The objective was to analyze data from both a disciplinary and a statistical standpoint. The Argonne National Laboratory program consisted of evaluating ten nuclear power plants that have operated for one year or longer. Each of the plants chosen was required, by the terms of the license granted, to conduct certain monitoring programs. Some plants are now obtaining additional data to serve their own interests. Do such programs meet the interests of ecologists concerned with the protection of the environment? What is the precision and accuracy of these results? What decisions can be made on the basis of the field data and how valid are such decisions? Answers to such questions would be of great value in establishing resource-effective monitoring requirements for future power plants. Also, a need for redesigning the programs at the existing power plants may arise.

As a result of the one-year effort, a series of reports has been prepared by the three laboratories. The Argonne report series has a general title of "An Evaluation of Environmental Data Relating to Selected Nuclear Power Plant Sites." The following is the list of the reports prepared by Argonne scientists.

Title

An Evaluation of Environmental Data Relating

to Selected Nuclear Power Plant Sites:

The Kewaunee Nuclear Power Plant Site

The Quad-Cities Nuclear Power Station Site

The Duane Arnold Energy Center Site

The Three Mile Island Nuclear Station Site

The Zion Nuclear Power Plant Site

The Prairie Island Nuclear Generating Site

The Nine Mile Polnt Nuelear Fower SLálun site

A Synthesis and Summary with Recommendations

$\begin{array}{lll}\text { August, } 1976 & \text { ANL/EIS-1 } \\ \text { August, 1976 } & \text { ANL/EIS-2 } \\ \text { August, 1976 } & \text { ANL/EIS-3 } \\ \text { August, 1976 } & \text { ANL/EIS-4 } \\ \text { November, 1976 } & \text { ANL/EIS-5 } \\ \text { November, 1976 } & \text { ANL/EIS-6 } \\ \text { October, 1976 } & \text { ANL/EIS-7 }\end{array}$

November, 1976

ANL/EIS-8

The ANL/EIS reports are informal documents distributed by the Division of Envirnnmenta1. Impact Studies of Argonne National Laboratory. 
Preface... . . . . . . . . . . . . . . . . . . . . . . . . . . .

List of Figures . . . . . . . . . . . . . . . . . . . . . . . . . .

List of Tables . . . . . . . . . . . . . . . . . . . . . . . . . .

INTRODUCTION • • • • • • • • • • • • • • • • • • • • • • • • • • • • 1

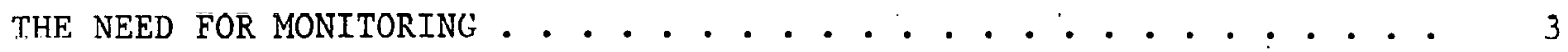

TOPICS OF STUDY • • • • • • • • • • • • • • • • • • • • • • • • • .

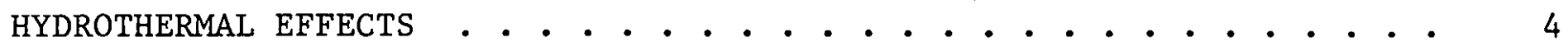

Nature and Extent of Environmental Predictions . . . . . . . . . . . . 4

Environmental Effects Observed through Monitoring . . . . . . . . . . . 5

Plume Size . . . . . . . . . . . . . . . . . . . . . . . . . . 5

Preoperational Plume Models . . . . . . . . . . . . . . . . . . 5

Conclusions and Criticisms Regarding Monitoring . . . . . . . . . . . . 7

Reflections on Methods of Data Collection . . . . . . . . . . . . . . 7

Reflections on Methods of Data Analysis . . . . . . . . . . . . . . . 9

Research and Development Needs . . . . . . . . . . . . . . . . . . 10

WATER QUALITY AND BIOCIDE EFFECTS. . . . . . . . . . . . . . . . . . . . 10

Nature and Extent of Environmental Predictions . . . . . . . . . . . . 10

Environmental Effects Observed through Monitoring . . . . . . . . . . . 11

Conclusions and Criticisms Regarding Monttor1ng . . . . . . . . . . . . 12

Reflections on Methods of Lata lollection . . . . . . . . . . . . . . 12

Reflections on Methods of Data Analysis . . . . . . . . . . . . . . . 12

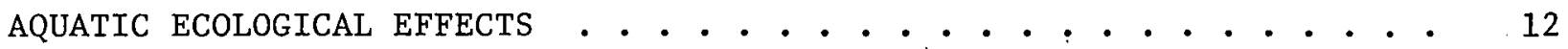

Nature and Extent of Environmental Impact Predictions . . . • . . . . . 12

Environmental Impacts ubserved through Monitoring . . . . . . . . . . 13

Conclusions and Criticisms Regarding Monitoring . . . . . . . . . . . . 13

Reflections on Methods of Data Collection . . . . . . . . . . . . . . 15

Reflections on Methods of Data Analysis . . . . . . . . . . . . . . 16

Research and Development Needs . . . . . . . . . . . . . . . . . . 22

TERRESTRIAL ECOLOGICAL EFFECTS • • • • • • • • • • • • • • • . • . 22

Nature and Extent of Environmental Predictions . • • . • • . . . . . . 22

Environmental Impacts Observed through Monitoring . . . . . . . . . . . 23

Conclusions and Criticisms Regarding Monitoring . • . • . . . . . . . . 23 


\section{FIGURES}

\section{Figure.}

Impact Model used for Zion Zooplankton Analysis.

2 Possible Responses to a Pulse Disturbance in a Stable Time Serites 


\section{TABLES}

Table

Page

1 Summary of the Topics Examined in the Evaluation of Nonradiological Environmental Monitoring at the Seven Selected Nuclear Power Plants............ . . . . . . . . . . . . . .

2 Analysis of Variance Table when Observations are Assumed to be Independent of Time . . . . . . . . . . . . . . . 


\title{
AN EVALUATION OF ENVIRONMENTAL DATA RELATING TO SELECTED NUCLEAR POWER PLANT SITES \\ A' SYNTHESIS AND SUMMARY WITH RECOMMENDATIONS
}

\begin{abstract}
Our analysis of the field data gathered during the monitoring programs at seven nuclear power plant sites show no significant ecological impacts. This conclusion is within the constraints of the quality of available data from these sites. Current monitoring programs are, however, not designed to meet the needs for statistical

- analysis and, consequently, the monitoring data are often ill-suited for modern statistical procedures. Recommendations are proposed for revising monitoring schemes so that more precise conclusions can be made from fewer field measurements.
\end{abstract}

\section{INTRODUCTION}

Data obtained from nonradiological environmental monitoring programs conducted at ten nuclear power plants that had been in operation for at least one year were examined. From the ten, seven sites were chosen for an in-depth study of environmental impacts other than radiological aspects. The sites chosen were those of the Kewaunee, Quad-Cities, Duane Arnold, Three Mile Island, Zion, Prairie Island, and Nine Mile Point Unit 1 nuclear power stations. of these, the Kewaunee, Quad-Cities, and Zion plants provided the best data allowing the most extensive analyses.

The monitoring data of concern were those pertaining to dispersion of heated-water effluent, water quality, biocide concentrations, and effects on terrestrial and aquatic biota. Not all plant sites were analyzed with respect to all environmental aspects; a matrix, shown in Table 1, notes the studies performed for each plant site.

The objectives of the program were:

1. To determine the extent of environmental. damage resulting:from operation of the nuclear power plant through analysis of the monitoring data.

2. To assess the validity of predictions of environmental impacts by comparing them with the impacts actually observed.

3. To assess the general adequacy of the monitoring programs. 
Table 1. Summary of the Topics Examined in the Evaluation of Fonradiological Ervironmental Monitoring at the Seven Selected Nuclear Forier Plants

\begin{tabular}{|c|c|c|c|c|c|c|c|}
\hline Name of Plant & $\begin{array}{l}\text { Thermal } \\
\text { Eydrology }\end{array}$ & \multicolumn{4}{|c|}{ Aquatic Ecology } & $\begin{array}{l}\text { Chemicals } \\
\text { and } \\
\text { Biocides }\end{array}$ & $\begin{array}{c}\text { Terrestrial } \\
\text { Ecology }\end{array}$ \\
\hline Kewaunee & $\mathrm{x}$ & $\mathrm{x}$ & $\mathrm{x}$ & $\mathrm{x}$ & & . & \\
\hline Quad Cities & $\mathrm{x}$ & & & & & $\mathrm{x}$ & \\
\hline Nine Mile Point & & & & & $\mathrm{x}$ & & \\
\hline Three Mile Island & & & & & & & $\mathrm{x}$ \\
\hline Duane Arnold & & & & & & $\mathrm{x}$ & \\
\hline
\end{tabular}


4. To identify the environmental impacts that would be of the greatest ecological concern.

5. To identify the need for the development of better methods for assessing environmental impact.

As the assessments of the data related to the seven sites were completed, the pertinent information was recorded and summarized in a series of companion reports (see Preface). This report presents an overall summary, conclusions, and recommendations; ilso included is a discussion of the general problem of establishing sampling schemes and of the use of proper analytical methods.

\section{THE NEED FOR MONITORING}

The environmental monitoring programs conducted at power plants have consisted of periodically collecting data on various biotic and abiotic factors at multiple locations. Data on the abundance and distribution of organisms at several trophic levels, on a number of water quality characteristics, and on the extent and configuration of thermal plumes have been obtained to check for environmental impacts. It was assumed that the significance of any environmental impact measured could then be assessed on the basis of the empirical evidence accumulated.

We believe that the purpose of biological monitoring at power plants is primarily to detect significant impacts of plant operation on the overall aquatic ecosystem or in any of its component parts (i.e., fish, zooplankton, benthos, phytoplankton and their subgroups). A significant detrimental impact is one that adversely changes the abundance or physiological state of organisms in such a way that the lost or impaired individuals are either not replaced or that the replacement is delayed too long and the ecosystem balance is upset.

Under this general definition, the important question in monitoring programs is not answered; namely, what constitutes a significant ecological impact? Therefore, when we suspect that there are unacceptable environmental changes affecting the biota, and want to take corrective or mitigative action, we must establish some limiting conditions for acceptable changes.

Some of the monitoring schemes have been developed under the assumption that monitoring is a research program which must result in a characterization and description of the environment. On the other hand, some of the monitoring requirements set by federal and state agencies seem to be the result of the philosophy that some kind of data collection at an operating power plant must be required. These widely held but contradictory approaches to monitoring make it very difficult to determine when a real need for monitoring exists, and what kinds of monitoring are necessary. This issue will be addressed in more detail later.

\section{TOPICS OF STUDY}

On the basis of available data, we concentrated on the following topics:

1) Hydrothermal dispersion 
2) Water quality and biocides

3) Aquatic ecology

a. Phytoplankton

b. Zooplankton

c. Benthos

d. Fish impingement

4) Terrestrial ecology

a. Avi.an mortality

b. Cooling-tower drift effects.

With the exception of the hydrothermal portion, the impact predictions were generally qualitative to semiquantitative in nature. In most of the cases the impact predictions on the biotic communities were less than definite for one or more of the following reasons: (a) the baseline characterization information was not available when the impact predictions were made, (b) the information was inadequate for making such assessments and predictions, or. (c) the state-of-the-art was not developed enough so that prediction of the nature and extent of impacts was possible.

\section{HYDROTHERMAL EFFECTS}

\section{NATURE AND EXंTENT OF ENVIRONMENTAL PREDICTIONS}

The discharge of heated water from a power plant to a lake or river raises questions of the size and shape of the plume within certain temperature bounds under various conditions of plant operation, receiving water flow and temperature, and meteorological conditions among others. In predicting the size, shape and temperature distribution within the thermal plume, the applicants (the companies seeking operating licenses) have typically employed analytical modeling or physical (hydraulic) modeling. When analytical modeling techniques were used, models were obtained from the open literature or else developed for the specific site at hand. These models were used to compute plume characteristics under numerous plant and environmental conditions. This was done to assess the effects on the plume of various plant loads, as well as ambient current, wind, and temperature conditions. The calculations showed that a wide range of plume characteristics was posslble depending on the input conditions, especially the various environmental conditions possible for that site. This wide range in plume characteristics was borne out by operational measurements. The models, employed at the time the Environmental Reports (ER) and Final Environmental Statements (FES) were developed for the plants investigated, were unvalidated and certain aspects of their development were theoretically unsound; this was typical of the state-of-the-art a few years ago, and perhaps today as well. For one site (Quad Cities), an undistorted physical model was used to predict plume dispersion under critical low river flows,

The Environmental Technical Specifications (ETS) required (for the three sites we studied in depth) the validation of the predictive models used in the ER. This requirement was based on the assessment presented in the FES. For the Kewaunee site, where an analytical model was used for predictions presented in the FES, the ETS also required the development of a model that could predict 
the measured thermal plumes for that site. As a result, the utility's consultants slightly modified and tuned the model used in the ER on the basis of the measured plume data to satisfy the ETS requirement.

ENVIRONMENTAL EFFECTS OBSERVED THROUGH MONITORING

$\underline{\text { Plume Size }}$

At the time of licensing, a " $3^{\circ} \mathrm{F}$ at 1000 feet (or equivalent area)" standard was required for the Kewaunee and Zion stations by the Federal EPA and the respective states involved. At Kewaunee, this standard was of ten exceeded during ful1-Dower operation. For two-unit $80 \%$ power at Zion, this standard was also exceeded. At Kewaunee, plume size varied with ambient current magnitude and direction as well as wind speed. Plumes directed northward were the largest due to significant shoreline and bottom interaction; plumes directed southward had the greatest dilution, since boundary interference was at a minimum. Plume areas for excess temperature ratio of $0.2\left(\theta / \theta_{0}=0.2\right)$ were about 100 acres. At Zion, for single unit operation ( $80 \%$ power), the surface areas within $4^{\circ} \mathrm{F}$ above-ambient isotherms under stratified and unstratified conditions varied at least three orders of magnitude. Single-unit operation generally satisfied the 72-acre mixing-zone limitation. Plume areas will generally exceed standards for two-unit operation ( $80 \%$ power) except for strongly stratified conditions. Plume areas can be as large as 1000 acres for two-unit operation under unstratified conditions. Double unit areas at the lower isotherms are about ten times the size of single-unit plumes. A severe competition between the two-unit plumes appears to occur for the cold entrainment water that is available.

Preoperational Plume Models

The Pritchard Model No. 2 (phenomenological approach) was used by both applicants (Kewaunee, Zion) in predicting the plume before plant operation. Unfortunately, these analytical model predictions were found to be inaccurate when compared to actual plume measurements.

At Kewaunee, for $\theta / \theta_{0} \geq 0.2$, the Pritchard Model predicted plume areas within a factor of five, plume widths by a factor of two, and isotherm lengths by a factor of three. A drastic increase in maximum plume width, distance to an isotherm and surface isotherm areas occurred for $\theta / \theta_{0} \leq 0.2$. The Pritchard Model underpredicted plume size in the near field (narrow cold plumes) and grossly overpredicted surface plume size when the measured surface areas exceeded 100 acres.

For Zion, the Pritchard Model was grossly optimistic (typically by an order of magnitude in surface areas) for all double-unit plumes and $80 \%$ of the single-unit plumes. The Pritchard predictions were accurate only for singleunit plumes when no stratification or recirculation occurred and the ambient current persisted in the longshore direction for a long period of time. In these statements we have ignored the significant error Pritchard made in simulating the length of the discharge outlet in his preoperational calculations; this error caused his predictions to be even more optimistic.

There are two basic reasons for the poor predictions in the Kewaunee and Zion cases: 
(A) Some processes that were not foreseen during preoperational calculations were observed to be operational at each site. At Kewaunee, the promontory into Lake Michigan from which the plant effluent discharged was ignored in terms of any substantive effect on the plume. Operational plume measurements indicated that the ambient current field was strongly affected by the presence of the promontory. The promontory caused the northward-directed plumes to wash against the shoreline, causing re-entrainment and higher temperatures. Currents directed southward were re-directed southeast by the promontory, causing the plume to be washed offshore into deeper water where more mixing could occur. The presence of the (unmodeled) promontory was a major cause of model/data discrepancies. Another unexpected problem at Kewaunee was the effect the changing lake level had on plume dispersion. At mean lake level $(577 \mathrm{ft}) *$ the water depth at the discharge inlet was five feet. All preoperational predictions were made with this mean lake level. During the two-year period of measurement observed lake levels ranged from $3.4 \mathrm{ft}$ to $9.9 \mathrm{ft}$. Plume data were sensitive to these different lake levels.

At the Zion plant, three important physical phenomena occurred regularly and were ignored in preoperational predictions. First, periods of reversing currents which bring back warm water to the plant site for re-entrainment were ignored. Such addition of reheated water to the plume area greatly increases the areas of the lower excess temperature isotherms. Second, recirculation of heated water back into the intake almost always occurs and can become significant during certain periods for two-unit operation. Third, stratification effects in summer were ignored; stratification reduces plume surface areas since the intake and discharge are submerged in colder water beneath the surface.

(B) There appeared to be systematic errors in the Pritchard Model itself, at least in the lower densimetric Froude number in the case of Kewaunee. In the near field at Kewaunee, plume lengths, widths, and areas were too small while for isotherms lower than $\theta / \Theta_{0}=0.2$, lengths, widths, and areas were very large. Subsequent calibration of the Pritchard Model to the plume data at Kewaunee removed most of the obvious biases in the model. Some correlations had to be changed slightly to allow this calibration to be done. The tuned (calibrated) model developed in the Zion case by the applicant (single-unit only) was satisfactory in the near field but not predictive in the far field; i.e., each case required parameters that could be obtained solely from the field measurements themselves.

For the site where a physical model was used to predict the heated effluent dispersion (Quad Cities) the discharge configuration was designed in the lab tank to satisfy state standards. Concerning validation of the laboratory model, the plume at the Quad Cities Nuclear Power Station was predicted by the physical model for low tlows on the Mississippi Kiver, whereas the actual river flows were above average for all field surveys. This inconsistency prevented direct comparisons of model predictions with field data.

*This is an International Great Lakes Datum. 
CONCLUSIONS AND CRITICISMS REGARDING MONITORING

Reflections on Methods of Data Collection

1) Plume mappings at the Kewaunee and Zion plants were generally satisfactory to delineate plume size and characteristics. The measurements techniques at Kewaunee posed some difficulty at times in obtaining rapid synoptic measurements during changing ambient conditions and in delineating plume from ambient waters during summer stratified conditions. These latter two problems will be addressed in more det:i il below.

2) It is essential that a monitoring program provide measurements of outlet temperature and flow rate in the discharge line. We must know the plant conditions precisely if any validation of the preoperational model is to be carried out. Either, additional calibrated instrumentation be placed in the plant outlet system and maintained for temperature measurement or a careful calibration be kept for the in-plant temperature-measurement systems. It has been our experience that the in-plant instruments are seldom calibrated carefully. We also suggest that plant discharge flow rate be verified, perhaps with tracer techniques. If the flow rate measurements are verified through independent measurements, then additional measurements need not be made until internal plant pump changes occur. On the other hand, the plant outlet temperature should always be monitored independently for each plume survey so that predictive models can be parameterized.

3) It is important to obtain synoptic measurements of the thermal plume. An ideal boat-mounted measurement system would contain multiple sensors to allow the simultaneous measurement of temperature at various depths--through either a fixed boom or by a towed thermistor chain attached to the boat. We feel it is satisfactory in operational monitoring to use one boat with a single sensor for surface measurements and a second boat for profile measurements. For smaller effluent discharges, a single boat may, under favorable (nearly constant) environmental conditions, carry out surface temperature and profiling operations in a reasonable time period. In most cases, the multiple sensor system will be helpful but not essential to operational monitoring. Synopticity, at least of surface plume measurements, is the overriding objective.

1) Tracer tcchniques are recumulnded for the measurement of plume characteristics under stratified ambient conditions. The continuous discharge of dye into the plant effluent water will tag the plume and allow it to be distinguished from the ambient waters during stratified periods. Otherwise, the far-field region of the plume can be totally masked by the apparent variation in ambient waters at that time.

5) For a precise mapping of the plume, a careful measurement study of the far field is needed; the far field is of greater importance during periods of current reversal, because of the consequent re-entrainment of heated water. into the plume which can significantly increase the temperature of the intermediate- and far-field regions of the plume. Current reversal periods occur frequentl.y. Pritchard notes that at Zion, some current reversal exists most of the time $(80 \%)$. During periods of re-entrainment for large plants, plume areas seem to increase by an order of magnitude (for the lower isotherms). Tracer techniques are helpful in delineating the plume dimensions at these lower isotherms. More careful attention also should be focused on how ambient conditions affect the far-field plume characteristics. 
6) A spatially variable ambient temperature should be determined when stratified ambient conditions occur. This variable ambient should include offshore and vertical components in order to obtain proper reference water temperatures. The customary procedure is to "eyeball" a single value of ambient temperature for each horizontal plane of measurements, and calculate excess temperatures for thermal plume mapping as the difference between a measured value and that single value for the ambient. It is more sensible to relate each plume temperature to the value of ambient temperature at a comparable hydrological condition (i.e., similar offshore distance and vertical displacement from the surface). In this way we are relating each plume temperature to the temperature that point would most probably have had if the plant were not in operation.

7) Measurement programs should be set up to monitor the power plant plume under widely varying conditions. Measurement periods should include surveys during each of the four seasons (the four season measurements are not necessary where seasonal changes are very small) to adequately assess the effects of different environmental conditions, malnly stratifled and unstratified. Measurements should also be made for various important plant operating conditions that are often forgotten, for example: (a) for the plant during the winter de-icing mode, and (b) for the plant in winter if there is a reduced flow and higher $\Delta \mathrm{T}$ across the condensers during any period. Each of the two situations occurred (de-icing mode at $\mathrm{Zion}$; reduced flow and greater $\Delta \mathrm{T}$ at Kewaunee) with larger than normal expected plumes, yet no measurements were taken for any of these cases. In a river situation, measurements should be taken for several different river flows, even if the season is the same.

8) A continuing controversy exists over the relative merits of employing moving boats or a fixed network of thermographs for the measurement of plume temperatures. Boat techniques have the flexibility to track the plume wherever it is located. This is certainly an advantage for heated effluent discharges into large open water bodies (large lakes, coastal arcas) where plumes ran have a large directional variability. Also the boat mcocurements can provide a relatively synoptic three-dimensional picture of the plume during the onehour period that it takes to carry out the survey. The major disadvantage of the boat surveys lies in their cost; only 15-20 separate surveys can be afforded in a year with present-day hydrothermal monitoring budgets. Plumes during the remainder of the year remain unmonitored.

The biggest advantage of the in situ system is that it can provide continuous measurements all year but by a sparse grid system ( 15-20 thermographs). This may be satisfactory for plumes in relatively small rivers (plume location is generally known), but may be unsatisfactory for plumes in large open water bodies subject to variable current dilections. In the lidter: rage, only a few of the thermographs will be expected to sample a thermal plume at a given time. Such a sparse network is insufficient to construct the plume configuration and profile at any time.

One subtle advantage of the in situ system is that in the long lerui, it can provide a probability estimate of temperature excesses at each in situ location. These probabilities could provide very coarse plots of frequency contours of particular isotherms. The intensive plume surveys also provide the same kind of frequency information, but only from a deterministic thermal 
plume model which would have to be calibrated to the 20-30 intensive plume surveys made at the site.

Actually, the hydrothermal monitoring ultimately must support the biological studies. Aquatic biologists are interested in the location, of the plume and its distribution of excess temperatures including the time they carry out their biological sampling. A moving boat with an $x-y$ plotter and recorder on board mapping the plume just prior to or during the biological survey appears to be a helpful approach. An offshore-directed transect, upcurrent of the plume, ca: provide a good sampling of the spatial ambient temperature distribution which is helpful in providing excess temperatures at the biological sampling locations. Most in situ systems have recording packages below the surface which are inaccessible to any immediate comparison for purposes of planning a biological survey. Remote transmission of continuous readings is very expensive as is the network of thermographs themselves. The field reliability of in situ thermograph systems is not high and continued servicing is required. Also, the determination of an ambient temperature for. the location of each in situ sensor in the plume is more difficult with a preset sparse network of thermographs.

Our preference for the overall hydrothermal needs is the boat survey system due to its flexibility. The in situ system may be attractive only for plumes in small rivers where the heated water extends essentially across the river.

\section{Reflections on Methods of Data Analysis}

Analysis of hydrothermal data should be directed towards establishing trends in the field data. We should attempt to learn the effect of the different operating conditions (e.g., power levels) and environmental conditions on the plume characteristics:. surface areas, centerline temperature decay, widths, depths and dilutions. An effective method to date has been to divide the 20 or 30 measured plumes into several different categories of operating and ambient conditions, each category having nearly the same kinds of plumes. A certain amount of subjectivity is required in the setting up of these categories, but that is inevitable.

Typical categories are: plumes directed upshore, plumes directed along shore, and plumes under near-stagnant conditions. Our major interest here is to find out if the data are internally self-consistent and to provide a reasonable explanation of the variation in plume characteristics with different outfail and ambient conditions. Also of major importance in determining the quality of the data is an examination of the plume data in comparison to data taken at a plant of similar size and similar outfall/ambient characteristics. If the trends in the two sets of data agree, then we have added more confidence in our measured plume data. An additional aim of the data analysis is to provide a framework in which to compare the predictions of analytical models.

A direct comparison of each set of plume data with the preoperational model may not be sufficiently revealing. In our opinion, an auxiliary test of the model would be helpful; we should compare the model to each of the categories of data developed in the data analysis; i.e., a single model prediction versus the several data sets in a particular category. The model prediction may be run with the average of input parameters in each category. In this way the 
stochastic errors in any individual set of measurements will not be emphasized. Moreover, trends in model/data discrepancies will be seen more easily.

RESEARCH AND DEVELOPMENT NEEDS

1. The state-of-the-art of plume prediction by analytical methods needs significant improvement. The greatest need is in the area of surface and shallow submerged discharges. Only general estimates of plume characteristics are currently possible. A recent critical review of surface discharge models concludes that the best available models predict surface areas within a factor of five, isotherm length within a factor of two, and isotherm width within a factor of two. Improvements in our predictive capability can be obtained by:

(a) further dcveloping numerical finite-difference models at. least in the near field. Such models are more general in formulation and can treat boundary effects,

(b) further develop and verify far-field models and their linkage to near-fleld effecls,

(c) carry out basic-parameters studies in the laboratory on plume dispersion from surface and shallow water discharges. These studies should help us understand the physics of these discharges and thereby further our modeling efforts.

2. The effect of far-field processes on plume dispersion is not well known. 'l'he coupling of wind and its effects on lake and coastal motion is a1so poorly understood. Without considerable additional research in this area, far-field plume models will still rely mainly on educated guesses about the processes of physical dispersion.

We are presently predicting the piume conservatively under extreille ui critical conditions; however, unpredictable ambient factors such as windinduced current effects and current reversals make tL lupussible to predict accurately the plume characteristics on a particular date. A particular prediction can be said to occur $X$ percent of the time but it cannot be determined on which days that prediction will occur. Only a much better understanding of far-field processes will improve our predictive capability.

\section{WATER-QUALITY AND BIOCIDE EFFECTS}

NATURE AND EXTENT OF ENVIRONMENTAL PREDICTIONS

Non-radioactive chemicals are used in the plants to regenerate the demineralizers that purify plant water supplies, to prevent fouling of heat exchangers, to maintain water quality, to inhibit corrosion, and for cleaning. As a result, plant effluents carry those chemicals added to the cooling water and auxiliary water streams or the reaction products thereof.

Because of its importance and particular chemical nature, the chlorinating agents, used as biocides, are considered potentially hazardous and are given detailed treatment in the assessment work. All three plants (Zion, Quad 
Cities, Duane Arnold) had planned to use chlorine as a biocide. However, Zion Station does not use any biocide.

In the FES of each of the three plants, the amount of chlorine to be used and the amount and kind of discharges to be added to the water body in the immediate vicinity of the plants were calculated. In the effluent, the chlorine residuals from biocide treatment usually varies in concentrations up to $0.1 \mathrm{ppm}$ maximum. If chlorination is necessary procedures call for the condenser inlet. water to be treated for a limited period several times a day. It was calculated that for the Duane Ainold power plant the concentration of residual available chlorine at the condenser outlet would not rise above about $0.1 \mathrm{ppm}$. For the Zion plant it was desired that the level in the effluent stream be kept below $0.05 \mathrm{ppm}$ maximum residual chlorine at the outlet. At the Quad Cities station the concentration of residual free chlorine at the exit of the half unit (the water box at the condenser midpoint) is not to exceed $1 \mathrm{ppm}$. According to the ETS the total free and residual chlorine in the discharge bay is limited to less than $0.1 \mathrm{ppm}$ at Quad Cities. This specification was made for a oncethrough cooling system which has since been changed to a closed-cycle operation.

In a closed-cycle operating system, the chemicals of like species present in the intake water are released at higher concentrations. For all three power plants the predicted levels of these concentrations under closed- or open-cycle cooling systems were presented in the respective FESs. The more detailed treatment of these predictions has been presented in the ANL-EIS series of reports for this program.

A control on $\mathrm{pH}$ around the neutral point is normally maintained at all plants. This is achieved by neutralizing the water in the system with acid or alkaline solutions. Chemicals from the demineralizer waste are added to the cooling water system for discharges in the water body. Among the other chemicals which are likely to be discharged in measurable concentrations are sulfates and phosphates.

A direct effect on the chemistry of the receiving water body was expected by the staff as a result of the thermal releases from the plants. Particularly, a reduction in dissolved oxygen concentration was recognized as a possible impact. Trace amounts of heavy metals and certain toxic substances were expected in the plant effluents, but no effect or impact due to these releases was predicted.

\section{ENVIRONMENTAL EFFECTS OBSERVED THROUGH MONITORING}

An evaluation of water quality, including biocide concentration, showed that (considering the natural environmental variability, and the detection limits of the measuring devices) no limits were exceeded to which we can assign adverse environmental impacts due to the operation of a power plant. The large volume of data collected and made available as a result of monitoring at each of the three nuclear power plants may depict the local environments, but it is not very helpful in determining the environmental impacts most likely to be attributed to the operation of power plants.

We examined the many chemical characteristics which have been measured for otudying poccible cffecto from the opcration of the plants. Particular attention was given to the effects of biocide, sulfuric acid, and phosphate- 
containing compounds. None of the data from the three plants shows distinguishable changes in sulfate or phosphate levels in the water body which exceed the natural variability and which can be shown to relate to plant operation. The data collected during the chlorination periods showed no measurable levels of excess chlorine in the discharge streams. The open water body (far-field locations) almost invariably showed no measurable residual chlorine. In making this evaluation, the majority of our effort was directed toward examining and exploring the data for possible environmental changes which were not predicted. We found that most of the water quality measurements were within the natural variations. One notable effect is the reduction in dissolved oxygen concentration in the discharge area of the Zion plant. This change could be related to the change in temperature and initial oxygen concentration. However, the absolute concentration of dissolved oxygen was not reduced below the 5-ppm level needed to sustain biological communities in the Great Lakes.

\section{CONCLUSIONS AND CRITICISMS REGARDING MONITORIN̈G}

\section{Reflections on Methods of Data Collection}

1. Many chemical measurements which were made as part of the monitoring programs may have no particular surveillance purpose. In the absence of any predicted impacts, most of such measurements are unnecessary.

2. The sampling frequency in space and time seems to be very high. A reduction is quite necessary.

\section{Reflections on Methods of Data Analysis}

In all the three cases pxamined, we found that nuclear power plant operation has not caused a detectable change in the water quality of the region. It is therefore recommended that evaluations, through simple-analysis of the water quality monitoring data, be conducted as often as pusslble and that decislonc be made about continuing the same scale of data collection following such evaluations.

\section{AQUATIC ECOLOGICAL EFFECTS}

NATURE AND EXTENT OF ENVIRONMENTAL IMPAC"I FKLLIICTIONS

In general, the environmental impact predictions for aquatic biology were qualitative. Most of the predictions were related to thermal effects on the plankton, benthos, and $\mathrm{fish}$ in the heated plume area.

It was recognized in the FES that fish losses through inpingement on the screens in the water-intake system would occur. Fish impingement losses were considered important in many instances but the effect of these losses on the environment was neither specified nor explained in the FES. Where predictions of impingement rates were specifically quantified (for instance, Nine Mile Point 1), the basis of these predictions was actual impingement data from the facility. But the quantification of these losses could only be gained through environmental monitoring during operation of the plant. 
It was evident from the various assessments in the FES that several individual judgments on environmental impacts due to power plant facility operation were made. These determinations did not indicate cause-effect relationships.

ENVIRONMENTAL IMPACTS OBSERVED THROUGH MONITORING

We used graphical and statistical time-series analysis techniques, linearmodel analysis methods, and qualitative approaches in evaluating the aquatic biology data.

The extensive and intensive analysis of the data led us to conclude that under the varying conditions of the environment, we could detect power-plantinduced changes (of large magnitudes only) in the abundance and distribution of the different groups of organisms. In the case of the Zion power plant, where we used advanced time-series analysis techniques, it was indicated that a change in the distribution of organisms in the planktonic group may be occurring in the vicinity of the plant. This indication, as an immediate short-term change, is inconclusive in the light of many perturbations and stresses produced by neighboring industrial facilities.

Tn all instances (i.e., Kewaunee, Zion, Prairie Island) our evaluation of plant-induced changes in the biotic groups showed no indication that a large change in the environment is occurring or has occurred. Although these nuclear plants have not been in operation long enough to reveal long-term deleterous effects, the present studies do not lead to a concerned prediction that any are developing. The cumulative effects of multiple industrial facilities on the water body were not considered in predicting or evaluating the short- and long-term effects.

Fish impingement losses were observed in varying quantities at various times of the year at all plant locations. At the Prairie Island plant, where a fish catch limit has been instituted under the ETS, several environmental events (defined as fish kills in excess of ETS limits) were reported during 1974-1975. For Zion and Nine Mile Point power plants, large numbers of alewife fish were killed. We cannot determine the full significance of these events on the local fisheries and the environment as a whole. Likewise, an evaluation of entralment losses and their effect on the environment was not made. Without reliable data on the size of the biotic populations, we have no way of translating this entrainment loss to an environmental concern.

CONCLUSIONS AND CRITICISMS REGARDING MONITORING

Our experience with the analysis of aquatic monitoring data in this project showed a need for the development of consistent sampling schemes, methods of sampling, reporting, and data analysis methods to determine the short- and long-term environmental effects which would cause concern. It should be recognized that the art of environmental assessment is still developing today. The use of empirical data as a means of inferring environmental impacts caused by the operation of a nuclear power plant has been cautious and costly. Emphasis has been placed primarily on the measurement of biotic communities to see whether environmental effects of large magnitude can be detccted. 
Even though we are somewhat bound by the approach of comparing preoperational to operational period data, it is necessary to evolve sampling schemes which will allow such quantitative comparisons to be made with capability in determining impacts. Our study indicates that the short-term environmental effects of power plants are either not distinguishable or that none are occurring. In many instances, however, the comparisons and associated inferences are based on poor environmental data representing the preoperational period followed by somewhat better data as a result of a modified collection scheme used during the operational period.

The organisms in the major biological groups are generally collected at stations in either a grid pattern or at points which have the intrinsic properties of providing observations in reference areas and stress areas of the system. Water depth is often a major consideration in selecting the sampling locations for biological monitoring. Variab1l1ty in bottom-sediment types appears to have been largely ignored when sampllng lucations have been selected.

With the present monitoring approach 1t is difficult to detect man-made impacts and differentiate them from natural perlurbations in the aquatic environment. Although the quantity of data collected is usually sufficient, the quantity of properly collected data is insufficient in most of the cases.

In general, the analysis of variance approach is taken whenever "eyeball" comparisons of data are made. Such an approach involves making strong assumptions, and this results in a dilution of the power of the inferences drawn. There is a distinct need to conceive the analytical model, whether qualitative or quantitative, prior to devising a sampling scheme. This approach is distinctly lacking in the programs we have evaluated.

It is appropriate that the thermal plume information be used in selecting the locations where biological measurements w1ll be utade, so that the cffects of the thermal effluents from power plants can be monitored. In the past the thermal plume measurement's and the biological measurements were made at different locations. In some cases, the reference otatione were in the thermal plume area, at least during part of the measurement period. At the Prairie Island plant (Kewaunee and Zion to a lesser extent) the number of biological sampling locations in the effluent area was too small.

In the process of performing uur analysis, wc found that several important points are not given the necessary attention when monitoring requirements were developed. These issues are fundamental and have been identified below:

(a) What is the purpose of monitoring?

(b) What is the intended use of monftoring information?

(c) What are the environmental characteristics that must be monitored?

(d) What is the expected magnitude and extent of impacts which must be measured and detected through the monitoring of the environment?

(e) How precise should the estimates of impacts be? How much uncertainty should be allowed in the detection of the impacts? 
The satisfactory resolving of these issues depends on vigorus technical explorations and management decisions. The time is very ripe to go ahead on both fronts and eliminate the haunting nature of issues (a)-(e). It can then be expected that the designing and implementation of environmental monitoring programs will be very objective and resource-effective.

Reflections on Methods of Data Collection

The following are conclusions and recommendations for effective environmental sampling to determine nuclear power plant impacts.

1) The minimal requirement for aquatic monitoring is a good basic overall plan designed for a statistical treatment of measurements of each major biological group (phytoplankton, zooplankton, benthos, and fish). All the samples should be taken according to the plan.

2) Short-term (immediate) responses to plant operation have been examined in many instances without considering a lag response. In our view, the proper analytical approach would be to design a sampling scheme capable of sensing a lagged response to power plant intervention. The effect in itself is likely to be a time-varying function of perhaps a nonlinear form. Our experience in the analysis of nonradiological data indicates that an increasing intensity of impacts may occur, but it may be detectable only over a long term.

3) There is currently a wide spectrum of quality and quantity of data collected at operating nuclear power facilities. There are various reasons for this. Many of the differences can be explained by the developing state-ofthe-art in equipment design and methods of measurement in ecological monitoring. The shortage of available trained personnel has been a factor in the past. Aquatic ecologists should standardize monitoring procedures where possible to enable all concerned to learn more and to carry out comparative analyses with better precision and higher degrees of success in detecting environmental impacts. .

4) Preoperational monitoring has been generally inadequate. More than one year's complete preoperational data (perhaps at least two years') should be obtained, with at least one year of monitoring prior to the start of construction. All preoperational monitoring should be geared to the basic analytical model to be used. A consistent sampling system for the major biotic groups should be followed throughout the entire sampling program.

5) iField equipment, particularly the sampling gear, should be carefully selected. Changes in type of gear, net sizes, etc., result in more harm than gain as far as the impact evaluation is concerned. If a change in gear must be made, both the old and the new equipment should be used for a considerable overlapping period so that comparative calibration can be attempted. We doubt, however, that an accurate calibration between gear types is possible.

6) Sampling stations need to be carefully selected on the basis of biological, physical and statistical considerations. Insofar as possible the same general station locations or areas should be sampled for the different biotic groups. Extreme caution and care should be used in selecting sampling stations on the basis of classification variables such as depth, bottom type, 
temperature differences, lake currents, river flow conditions, etc. Sufficient sampling stations in the stress area should be established to obtain an estimate of plant effects on the biota.

7) Depth effects on the distribution of biotic organisms is a major factor considered in the present sampling programs. We know a priori that the water column characteristics play a major role in determining the distribution of the organisms. Unless we can formulate a hypothesis of differential plant impact with increasing depth, taking samples at several depths is unnecessary. Adequate sampling at appropriate depths will still be needed, but in general, data from fewer depths would be sufficient.

8) A coordinated effort to combine the monitoring and mapping requirements of thermal plumes and measurement of ecological characteristics is needed. This is extremely important when the determination of the locaclon of a biological sampling station is made.

9) It is not essential that the organisms (with the exception of $f$ ish) be identified to the species level, although classifying them into major subgroups at the genus level is necessary for any meaningful analysis. If an impact is detected within a group, additional work may be necessary to identify organisms to species in order to determine the significance of the change.

10) The population estimates of local adult, juvenile and larval fishes do not have the needed precision to allow a determination of significance of the impact of plant-caused losses in the local fishery resources, i.e., we cannot properly assess the significance of plant-induced fish losses without adequate data on fish resiliency (e.g., total population estimate, year classes, larvae, food, cte.).

11) Trawling for varying lengths of time introduces a large error. Such a sampling approach has resulted in reducing the precisiun in detecting impact 3. Apparently we still need to establish consistent measurement illethods.

\section{Reflections on Methods of Data Analysis}

There are at least two approaches to carrying out a monitoring program to determine the environmental impacts of a proposed action. In the first, it is necessary to deflue the uljective and the need for data collccilon. Then IL is important to develop a plan based on the objective which will include the experimental/sampling design and carry out the analyses using methods selected when the program was designed. The second approach is to collect data and then carry out exploratory data analysis to determine if something is of interest. Then modeling is attempted to include the relationships emplrically obtained and to represent the behavior of the process which produced the data obtained.

The monitoring programs and analyses of monitoring data collected for nuclear power plants seem to follow the second approach. Regardless of the approach taken, proper analyses (even iterative) are necessary to draw valid conclusions. Feedback is not operative unless adequate and meaningful analyses of the data are conducted. 
Our conclusions and recommendations, which reflect on the data-analysis aspects of aquatic environmental surveillance, are listed below.

1) Emphasis needs to be placed on the data analysis and the close examination of assumptions underlying the analysis. As a result of our work we conclude and recommend that paired differences of the log densities between control and stress stations, or some equivalent transformation, be used in analyzing the data. The use of differencing and transforming not only seems to reduce seasonality, but also greatly reduces serial correlations over time.

2) We suggest a regression analysis for the determination of impacts due to power plant operation. In brief, the following regression model to relate density of organisms of control $\left(X_{i t}\right)$ and stress $\left(Y_{i t}\right)$ stations at time point $t$ before the plant is operational:

$$
Y_{i t}=A+\sum_{i=1}^{S} B_{i}\left(x_{i t}-\bar{x}_{i}\right)+e_{i t}
$$

where $A=$ intercept constant

$s=$ number of control stations

$\mathrm{Y}_{\text {it }}=$ densities of organisms of stations at time $t$

$\mathrm{B}_{i}=\begin{aligned} & \text { regression coefficients relating the reference stations to stress } \\ & \text { stations }\end{aligned}$

$e_{i t}=$ random errors assumed to be NID $\left(0, \sigma_{e}{ }^{2}\right)$

The estimates of $B_{i}$ coefficients are obtained by the least squares method using the preoperational data. Using the preoperational estimates of the coefficients in Equation 1 and the observed $X_{i t}$-values for the operational period, a prediction, $\hat{\mathrm{Y}}_{\text {it }^{\prime}}$, is obtained, i.e.,

$$
\hat{\mathrm{Y}}_{i t^{\prime}}=\hat{A}+\sum_{i=1}^{S} \hat{B}_{i}\left(X_{i t^{\prime}}-\bar{X}_{i}\right)
$$

A comparison of values of $\hat{\mathrm{Y}}_{i^{\prime}}{ }^{-}$with $\mathrm{Y}_{i t^{\prime}}{ }^{\prime}$ during operational periods can be made to determine whether an impact of statistical significance has occurred.

A principal drawback of this procedure is that the independent variables are also measured with errors as large as the dependent variables. This may restrict the sensitivity of the method in detecting impacts of smaller magnitude. Only a small effort was vested in attempting to use this approach for Zion data; therefore, it is not possible to comment on the suitability of this analysis in the case of $\mathrm{Zion}$. It would be beneficial if a complete analysis under this approach were made.

3) From our experience in ánalyzing data from various power plants, we find that it is very difficult to find evidence of an impact, because of the number of sampling locations involved and the tendency for time interactions to be significant. These interactions are not necessarily caused by the plant uperat1on. Thus methods for combining the results from several sampling loca- 
tions and then testing them for impact need to be examined. Table 2 combines data for station pairs by water depths for an analysis of Variance (ANOVA) to test impact hypotheses (here $\mathrm{n}_{\mathrm{a}}=\mathrm{n}_{\mathrm{b}}=\mathrm{n}$ ).

The overall test of impact using the above ANOVA is $F=$ MS(BA)/MS (Time/BA) if there are no $\mathrm{BA} \times \mathrm{S}$ and $\mathrm{BA} \times \mathrm{D}$ interactions. However, if either $\mathrm{BA} \times \mathrm{S}$ or $B A \times D$ are significant, then the results are not so clear-cut and it may be necessary to examine impact by depth and/or station pair, as was done for the total zooplankton data for the Zion site. Note, that if the BA $\times \mathrm{D}$ interaction is not significant it may be an indication that samples only need be taken at one or two depths.

It should be pointed out here that the ANOVA given in Table 2 may not be the most appropriate method for including depth in the analysis. That is, instead of treating water depth as another factor in an ANOVA, it may be more reasonable, since the data at different water-depths are highly correlated, to treat the data taken at the same time at each of the depths as a multivariate observation. One could then perform a multivariate analysis of variance (MANOVA) analogous to the ANOVA for one depth. This approach would involve fewer assumptions than treating depth as another factor in the ANOVA. The MANOVA would, in effect, test the simultaneous effect of the intervention at the three depths of measurement.

Table 2. Analysis of Variance (ANOVA) Table When Observations Are Assumed to be Independent of Time

\begin{tabular}{|c|c|c|}
\hline Source & $\mathrm{df}$ & EMS \\
\hline BA & 1 & $\sigma_{\mathrm{e}}^{2}+\operatorname{sn} \sigma_{\mathrm{bad}}^{2}+d n \sigma_{\mathrm{bas}}^{2}+s d \sigma_{t}^{2}+\operatorname{sdn}\left(\sum B A_{k}^{2}\right)$ \\
\hline Time/BA & $2 n-2$ & $\sigma_{e}^{2}+s d \sigma_{t}^{2}$ \\
\hline Station (S) & $s-1$ & $\sigma_{\mathrm{e}}^{2}+2 n \sigma_{\mathrm{sd}}^{2}+2 \mathrm{nd} \sigma_{\mathrm{s}}^{2}$ \\
\hline Depth (D) & $d-1$ & $\sigma_{\mathrm{e}}^{2}+2 n \sigma_{\mathrm{sd}}^{2}+2 n s \sigma_{\mathrm{d}}^{2}$ \\
\hline $\mathrm{RA} \times \mathrm{S}$ & $s-1$ & $\sigma_{e}^{2}+\operatorname{dn} \sigma_{\text {has }}^{2}$ \\
\hline $\mathrm{BA} \times \mathrm{D}$ & $d-1$ & $\sigma_{\mathrm{e}}^{2}+\operatorname{sn} \sigma_{\mathrm{bad}}^{2}$ \\
\hline$S \times D$ & $(s-1)(d-1)$ & $\sigma_{e}^{2}+2 n \sigma_{s d}^{2}$ \\
\hline Error & $\begin{array}{l}(s d-1)(2 n-2) \\
+(s-1)(d-1)\end{array}$ & $\sigma_{\mathrm{e}}^{2}$ \\
\hline
\end{tabular}


4) Another technique for combining data taken at several depths and stations that might prove useful is to use a response surface approach. For example, take the Zion sampling design and consider depths as the $X$ axis and distance to the various stations as the $\mathrm{Y}$ axis, i.e.,

is

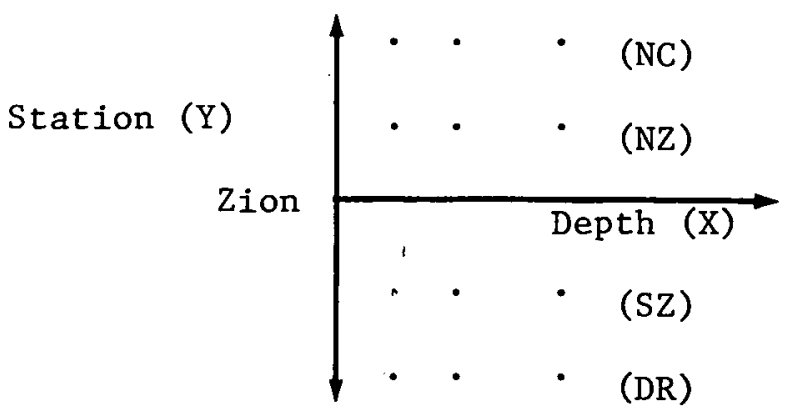

Thus, for each month ( $t$ ) there are 12 observations for the various (X, $Y$ ) coordinates. The following model may then be fit over time for a particular variable (e.g., z).

$$
z_{t}=a+B_{1} X_{t}+B_{2} X_{t}^{2}+B_{3} Y_{t}+B_{4} Y_{t}^{2}+B_{5}(X Y)_{t}+e_{t}
$$

Equation 3 can be fit before and after plant operation begins to determine if the shape of the response surface has changed. For example, before plant operation, the coefficient on the $(X Y)_{t}$ term in $E q .3, B_{5}$, may not be significantly different from zero. However, after plant operation begins $B_{5}$ may become significant due to an impact on the stress stations $\mathrm{NZ}$ and $\mathrm{SZ}$. In addition, the model given in Eq. 3 might be used to help determine where to put sampling stations, e.g., should several depths be sampled or are one or two depths sufficient?

5) We used an integrated moving average process to fit separately the time series In SZ - In DR and In NZ - In NC at three meters depth at the Zion site. However, no attempt was made to combine the data from the two time series. In the future if the time series approach is used, some thought should be given as to how to combine the data from several station pairs and then to perform an overall test of impact. (As an aside, a procedure for determining sample size when using the time series approach should also be considered.)

In the Zion report, we investigated the following nul1 hypotheses: $\mu_{\text {before }}=\mu_{\text {after }}$ (when assuming In NZ - In NC observations were independent over time) and $\delta=0$ (when using the integrated moving average time series approach). Obviously, these are only two of a multitude of null hypotheses and models that could be tested. For example, at Zion site for in (SZ) In(DR) total zooplankton 1 p.ve1s, the model (Fig. 1) for impact was also briefly considered; i.e., the impact, $\delta$, does not occur immediately with plant operation (August, 1973) but only after a time period T. Certainly, additional hypotheses and models will have to be examined. In determining these hypotheses and models, assistance should be solicited from persons knowledgeable (e.g., marine biologists) about the possible impacts of environmental variables of nuclear power plants. For example: "is the before and after overall average density of phytoplankton. what really should be tested or would it be more 


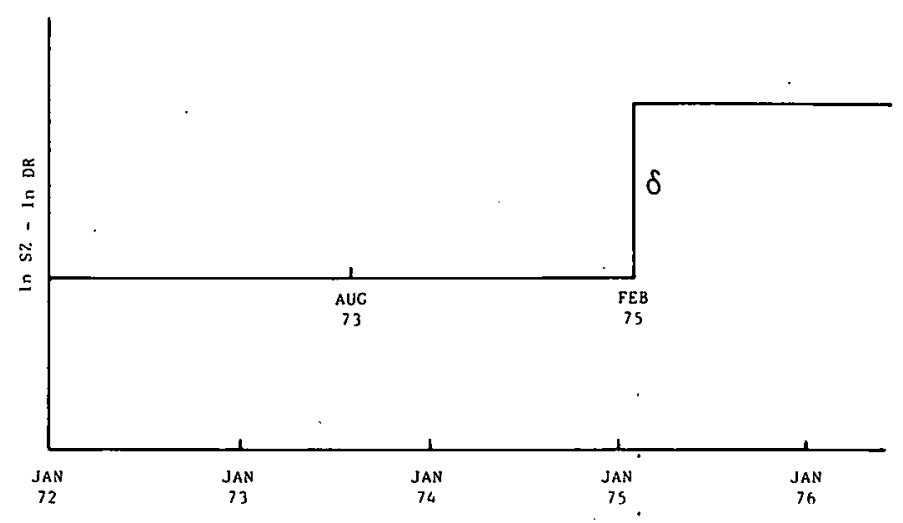

Fig. 1. Impact Model used for Zion Zooplankton Ana1ysis.

reasonable to test only the peak phytoplankton levels during the years before and after plant operation?" and "is the impact likely to be a sudden jump in level $\delta$, a slow increase over several years, or wlll only lik yeatly peak levels be affected?"

6) Figure 2 gives a postulated response function depicting six possible conditions showing the changes in measurement variable as a result of perturbation due to the operation of the plant. A unified summary defining the problem of impact measurements and statistical analysis can be mathematically represented as follows:

$$
y_{t}=\delta+g(\underline{\alpha}, t)+f(\underline{\beta}, t)+u_{t}
$$

where $y_{t}$ is the realization of a time series consisting of a sultable transformation of the environmental characteristics of interest,

$\delta$ is a location parameter,

$g(\underline{\alpha}, t)$ is a time-dependent function that models the environmental process determining the state of the environmental characteristics,

$f(B, t)$ is a time-dependent response function that models the environmental changes due to the operation of a facility,

$u_{t}$ is an error term which either is NID $\left(0, \sigma_{u}^{2}\right)$ or is given by an ARIMA process [ARIMA $=$ (Autoregressive integrated moving average)].

In this unified form, the $g(\underline{\alpha}, t)$ is the function which models the environmental characteristics of interest, and $f(\underline{\beta}, t)$ is the function which models the expected change in the environment. It is necessary to estimate $g(\underline{\alpha}, t)$ so that the environmental impact can be estimated in the form of $f(\underline{\beta}, \bar{t})$. Both of these functions could be linear, intrinsic linear, or non-linear in form. Depending on the shape and the explicit forms of these functions, appropriate computational algorithms may be used to estimate the coefficients of the $g(\underline{\alpha}, t)$ and $f(\underline{\beta}, t)$.

This unified theory includes linear models and time-series analysis approaches as special cases to the generalized scheme. 


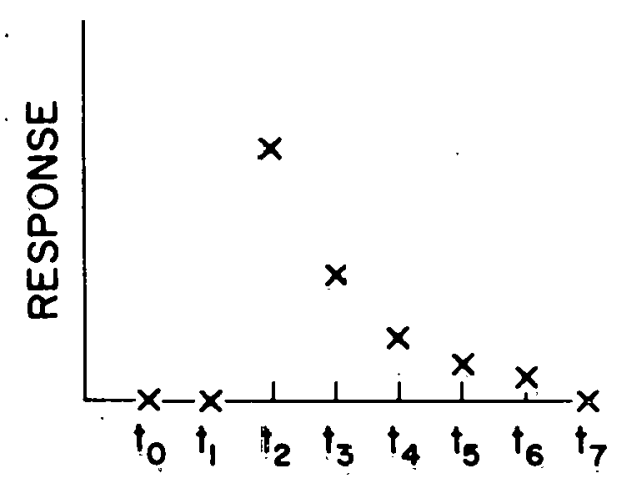

(a)

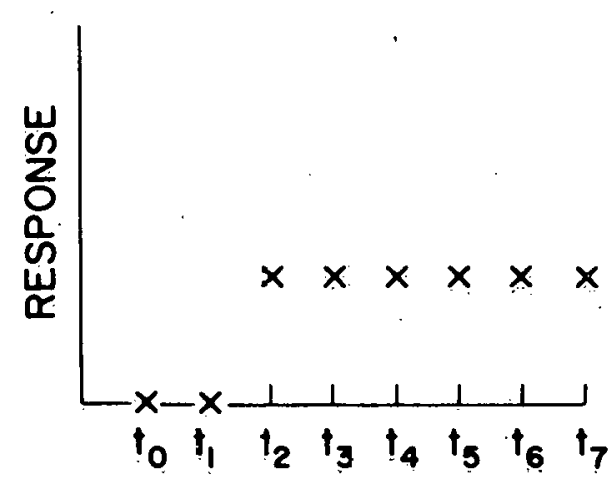

(d)

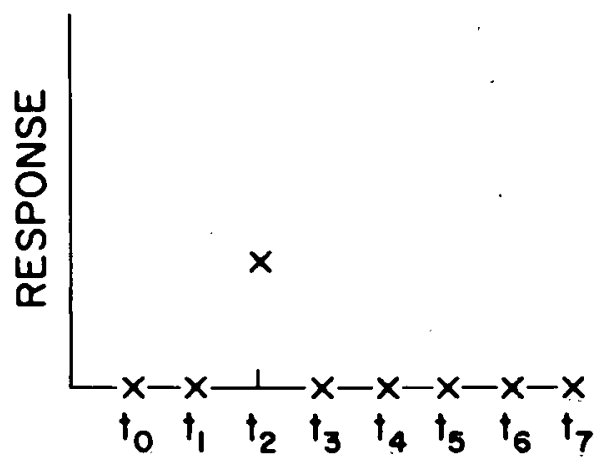

(b)

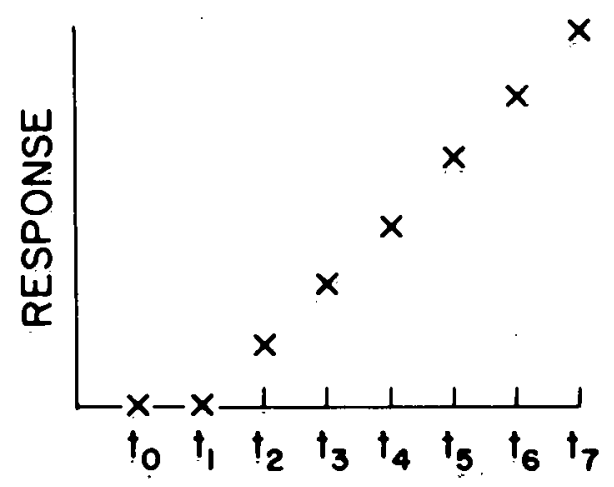

(e)

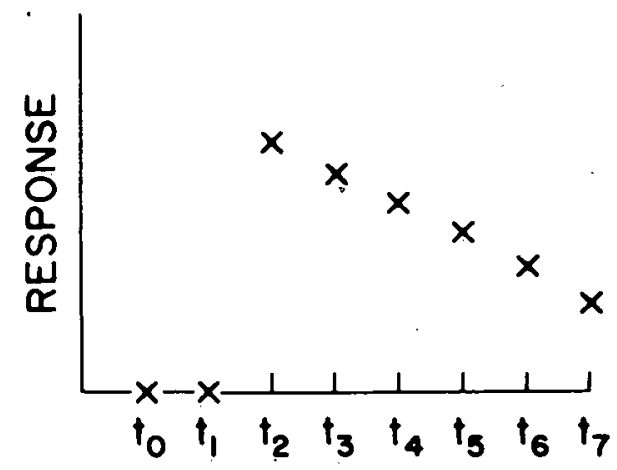

(c)

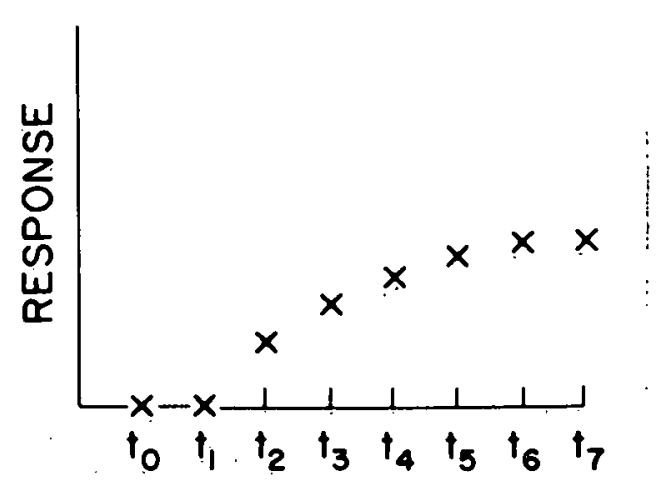

(f)

Fịg. 2. Possible Responses to a Pulse Disturbance in a Stable Time Series. 
RESEARCH AND DEVELOPMENT NEEDS

1. Of urgent importance is the need to define and determine: what is an ecologically significant impact?

2. There is a distinct need to determine what ecological characteristics should be monitored. For the biological trophic structure, which is highly complex, we should determine taxonomic and/or functional groups so that sitespecific biological characteristics for environmental monitoring can be chosen.

3. Sampling schemes that are sensitive and precise enough to detect environmental impacts due to power plant operation should be developed. Levels of required precision should be predetermined. The following questions should be asked and answered in the development of environmental surveillance programs.

(a) For what period of time and what frequency should the environmental variables be sampled both before and during the plant operation?

(b) How many stations should be sampled to detect environmental changes which may occur because of facilily operation?

(c) Where should the stations be located?

4. The need to develop and/or adopt data-analysis methods for determining environmental impacts should be given a high priority. How should the data be analyzed? Can adjustment for seasonality in data be made so that the impact of plant operation can be more easily assessed?

5. Investigations regarding the uses of mathematical models for environmental impacts should be carried out. Equation 4 presents a unified summary of environmental impact analysis mudels. The explicit formulation of the mathematical functions and the testing of their validity should be carried out.

6. The cumulative effects of several power plants on a local and regional basis should be investigated for the determination of environmental impacts. other environmental stressors could be integrated.

7. There is a need to develop methods to predict long-term ecological impacts using the literature data and the environmental monitoring data from one or more power plant sites etc.

8. There is a need for laboratory studies to determine the chronic effects of short-term exposure to power plant effluents, and to develop methods of extrapolating laboratory results to the natural systems.

\section{TERRESTRIAL ECOLOGICAL EFFECTS}

\section{NATURE AND EXTENT OF ENVIRONMENTAL IMPACT PREDICTIONS}

In general, the environmental impacts for terrestrial ecology were qualitative. Of principal concern has been (1) the impacts of cooling-tower drifts on local crops and vegetation, and (2) bird kills from collisions with the cooling towers and the transmission lines. 
In the Three Mile Island plant FES, the effect of salt drift from the cooling towers was extensively discussed, although the salt drift was not expected to adversely impact local agricultural crops or natural vegetation. Avian mortality during the spring and fall migration periods was expected to have an impact that may be regarded as significant.

\section{ENVIRONMENTAL IMPACTS OBSERVED THROUGH MONITORING}

Only a small amount of operational data on the terrestrial vegetation distribution and avian mortality were available when we evaluated the nature and extent of the impacts due to the operation of Prairie Island and Three Mile Island plants.

The qualitative comparisons of the ground cover for herbaceous vegetation-number of stems per plot, the tree-trunk diameter at breast height, and visible pathological signs on leafy vegetation--revealed no detectable impacts of the cooling-tower salt drift on the surrounding vegetation.

Bird kills from collisions with the cooling towers or transmission lines were only a few in numbers. The small number of birds killed was interpreted as a minimal impact from the operation of the power plants.

\section{CONCLUSIONS AND CRITICISMS REGARDING MONITORING}

It appears that the environmental impacts on the terrestrial ecosystem are primarily those that occur during the construction period. Continuing impact due to salt-drift depositions and avain mortality are not short-term effects. The long-term impact on a local scale could be measured only if the edaphic and vegetation tissues are monitored for changes in chemical composition. Although such changes are expected to be restricted to the immediate vicinity of the power plant cooling towers, in a unique terrestrial environment such effects may be regarded as significant. Measuring tree-trunk diameter at breast-height is insensitive to determining the salt-drift effects. 